\title{
Analysis of Window Components Affecting U-Value Using Thermal Transmittance Test Results and Multiple Linear Regression Analysis
}

\author{
Sang-Tae No ${ }^{1}{ }^{1}$ and Jun-Sik Seo ${ }^{2}$ \\ ${ }^{1}$ School of Architecture, Korea National University of Transportation, Chungju, Republic of Korea \\ ${ }^{2}$ Korea Conformity Laboratories, Seoul, Republic of Korea \\ Correspondence should be addressed to Sang-Tae No; nst1123@gmail.com
}

Received 22 December 2017; Accepted 28 February 2018; Published 2 May 2018

Academic Editor: Geun Y. Yun

Copyright (c) 2018 Sang-Tae No and Jun-Sik Seo. This is an open access article distributed under the Creative Commons Attribution License, which permits unrestricted use, distribution, and reproduction in any medium, provided the original work is properly cited.

\begin{abstract}
Currently, global warming is accelerating, and many countries are trying to reduce greenhouse emission by enforcing low energy building. And the thermal performance of the windows is one of the factors that greatly influence the heating and cooling energy consumption of buildings. According to the development of the window system, the thermal performance of the windows is greatly improved. There are simulations and tests for window thermal performance evaluation techniques, but both are time consuming and costly. The purpose of this study is to develop a convenient method of predicting $U$-value at the window system design stage by multiple linear regression analysis. $532 U$-value test results were collected, and window system components were set as independent values. As a result, the number of windows (single or double) among the components of the window has the greatest effect on the $U$-value. In this research, two regression equations for predicting $U$-value of window system were suggested, and the estimated standard errors of equations were 0.2569 in single window and 0.2039 in double window.
\end{abstract}

\section{Background}

In June 2014, the South Korean government confirmed its plan to reduce the country's greenhouse gas emission by an average of $37 \%$ by 2030 . In the field of construction, Ministry of Land, Infrastructure and Transport of Korea is making strategic effort to reduce energy consumption by leading existing buildings to reinforce heat insulation through green remodeling, applying enhanced insulation standards to new buildings, building zeroenergy houses (passive houses), and requiring 50\% reduction of air-conditioning and heating energy [1].

In cities like Seoul in which buildings and population are concentrated, $90.9 \%$ of the greenhouse emission is from energy demand and $68.5 \%$ of it is from air-conditioning and heating for buildings [2]. The largest percentage of energy when air-conditioning and heating buildings is consumed as heat energy that transfers via external walls, especially heat transfer through windows, which have particularly low thermal performance. For that reason, fitting manufacturers around the world are striving to develop functional windows with improved performance. Heat insulation technologies for windows have seen various developments from multilayer glass to argon gas, PVC spacer, and now high-insulation super window. During window development processes, these insulation technologies are combined in various ways. And, thermal performance is tested according to the specific combination of the technical elements, and as the most accurate method to conduct such tests, thermal chambers are used. However, using a thermal chamber is difficult in the design stage due to time and cost limitations. Although $2 \mathrm{D}$ and $3 \mathrm{D}$ thermal CFD analysis simulations are available, it is difficult to take into account the production error and requires a considerable amount of time and costs. Therefore, a simple method needs to be developed to evaluate the thermal performance of windows in the design stage. 


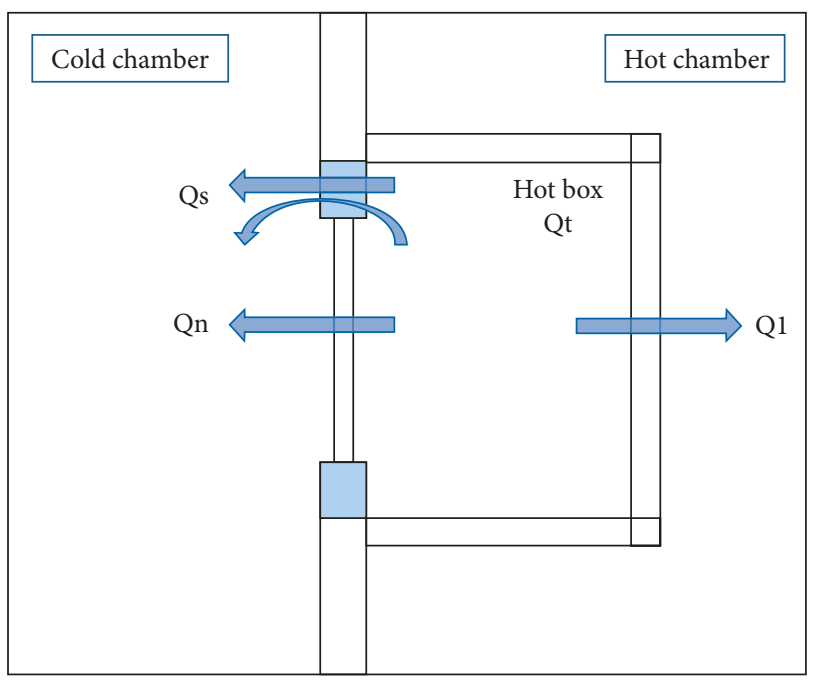

FIgURE 1: Measurement theory of thermal transmittance.

\section{Objectives}

As mentioned earlier, it is necessary to develop a simple method of evaluating thermal performance of windows that is cost and time effective and can be easily applied during the design stage of window systems. This study chose to utilize data ( $U$-value) from various tests related to the thermal performance of windows by using a thermal chamber based on KSF 2278 (standard test method for thermal resistance for windows and doors). After identifying various components of window systems that are believed to influence thermal performance of window systems, in this study, a multiple linear regression analysis was conducted to investigate the extent of the effects of those components on $U$-value. And then, based on the results, this study proposed a regression equation with which we can roughly estimate the thermal transmission coefficients according to components of the window system.

\section{Literature Review}

Earlier literature related to thermal transmission coefficients of window systems reviewed in this study is as follows.

Asdrubali and Baldinelli showed their work of "Thermal transmittance measurements with the hot box method: calibration, experimental procedures, and uncertainty analyses of three different approaches." In this research, the window system thermal transmittance test standards of world were compared and analyzed. The calibration and experimental procedures can be performed, taking into account three standards for calibrating hot boxes: European EN ISO 8990; American ASTM C1363-05; and Russian GOST 26602.1-99. Results showed that although EN ISO 8990 and ASTM C1363-05 are similar in terms of procedure definition, methodology of thermal transmittance calculation, and level of uncertainty, GOST 26602.1-99 differs from the others [3].

Yoo et al. showed their work of "Thermal transmittance of window systems and effects on building heating energy use and energy efficiency ratings in South Korea." And they measured the thermal performance ( $U$-factor) of different window systems and analyzed their effects on energy savings. All systems considered in this study helped improve insulating performance. The results showed that the use of temperable, low-e glazed units helped achieve 19.9\%, 17.1\%, and $15.2 \%$ energy savings in the study areas in the central and southern regions in South Korea and in Jeju Island [4].

S.-H. Kim et al. showed their work of "A study on proposes of energy analysis indicator by the window elements of office buildings in Korea." This study confirmed that the variation of the window elements affect to energy consumption through previous studies, and this should be considered in window design according to the policies and guidelines. The window elements were divided into performance elements of the windows and architectural/equipment plan element. By analyzing the energy consumption by changing the element, this study confirmed the variation of energy consumption by using the COMFEN4.0 simulation tool [5].

No et al. showed a study on evaluation of the thermal performance of window systems using both simulations and experiments. In this study, for 12 curtain walls, the mean temperature difference between computer simulations and the mock-up tests was about $2.6^{\circ} \mathrm{C}$. The simulation method (NFRC) considering convection and radiation showed closer result to the mock-up test than the conventional simulation method. This study proposed a method adjusting the simulation result to the test result by changing the convective film coefficients of the frame and glazing to find the optimal convective film coefficients for the chamber. To verify proposed the average convective film coefficients, additional thermal mock-up tests and simulations were performed. The simulation using the average convective film coefficients showed better agreement with the mock-up result [6].

Although the effects of window system components on thermal performance of the windows and building energy have been analyzed, research in which the thermal performance was evaluated by using data from different window tests is limited. Furthermore, earlier research that statistically analyzed the thermal performance data is rare.

\section{Measurement of Window System U-Value}

Window heat transmission can be measured by using either the guarded hot box or calibrated hot box method.

The Korean Industrial Standards (KS) of South Korea applies KSF 2278 (standard test method for thermal resistance for windows and doors) [7], according to which thermal transmission coefficients of windows are measured in South Korea. Similar international standards include ISO 12567-1 (Thermal performance of windows and doors-determination of thermal transmittance by the hot box method-Part 1: complete windows and doors) [8] and ISO 8990 (Thermal insulation-determination of steady-state thermal transmission properties-calibrated and guarded hot box) [9].

To measure thermal transmission coefficients of windows according to KSF 2278, from the hot box heating (Qt), which is measured using a cold/hot chamber as shown in Figure 1, calibrated hot box heat (Q1) and calibrated specimen fixing panel heat (Qs) are subtracted in order to obtain heat transmittance of specimen (Qn). Then, Qn is 

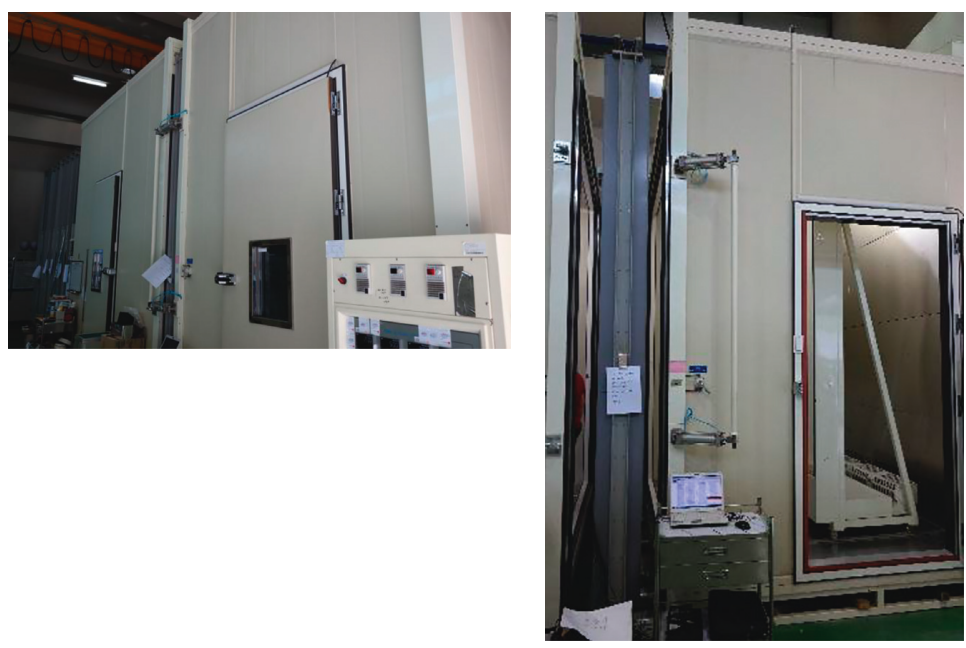

(a)

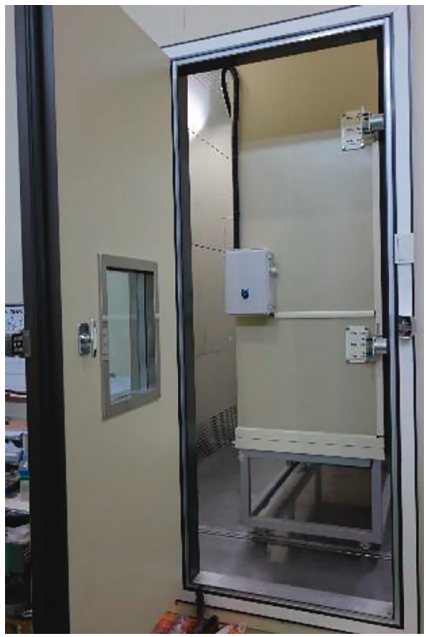

(c) (b)

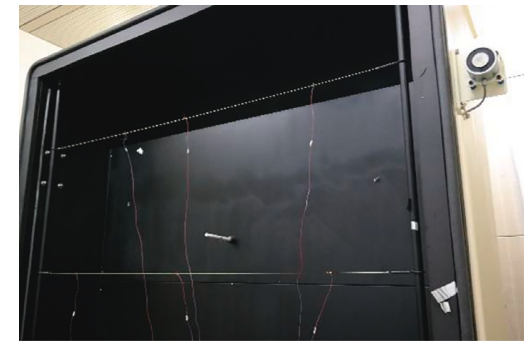

(d)

Figure 2: (a) Test equipment for thermal transmittance, (b) cold chamber of test equipment, (c) hot chamber of test equipment, and (d) hot box in hot chamber of test equipment.

divided by the difference in air temperature between either side of the chamber and the area of heat transmission of the specimen, and the final thermal transmission coefficient ( $U$-value) is obtained. As a unit of measurement for the thermal transmission coefficients, $\mathrm{W} / \mathrm{m}^{2} \mathrm{~K}$ is used. Other specific measuring conditions that need to be taken into account during the test include steady state, chamber temperature condition, heating box calibration, and temperature and wind velocity measurement. However, these factors are not relevant in this study and are described in detail in KSF 2278 or ISO 12567-1. Figures 2(a)-2(d) show the exterior of equipment that is being used for measuring thermal transmission coefficients of a window system, such as entire chamber, cold/hot chamber, and hot box in hot chamber.

\section{Multiple Linear Regression Analysis}

5.1. Data Coding for Analysis. KCL (Korea Conformity Laboratories) in South Korea owns five units of the equipment shown in Figure 2 and has conducted various tests related to $U$-value of window systems. As a result, the organization secured $548 U$-value test results between September 2014 and August 2016 [10]. Table 1 shows examples of data formats related to 532 window system components, after excluding cases in which the components were not usual, and the thermal transmission coefficients.

As shown in Table 1, KCL categorizes window system components into frame material, window opening type, window number (single or double), frame width, glazing detail, and spacer material and manages data accordingly. Moreover, the data of each category are divided into different options or numeric values. To conduct a multiple regression analysis by using these data, it requires coding in order to classify each data as a nominal scale variable or ratio scale variable. Table 2 shows settings and coding of nominal scale variables for multiple regression analysis $[11,12]$.

There are six options for frame materials, which were coded in 1 and 0 from the variable label FR_1 to 5. There were six options for window opening type, which were coded from the variable label OP_1 to 5. There were three 
TABLe 1: Examples of $U$-value test results and window components.

\begin{tabular}{|c|c|c|c|c|c|c|c|c|}
\hline $\begin{array}{l}\text { Specimen } \\
\text { number }\end{array}$ & Frame material & $\begin{array}{l}\text { Window } \\
\text { opening } \\
\text { type }\end{array}$ & $\begin{array}{l}\text { Single or } \\
\text { double } \\
\text { window }\end{array}$ & $\begin{array}{l}\text { Frame } \\
\text { width } \\
(\mathrm{mm})\end{array}$ & $\begin{array}{l}\text { Glazing detail (material and } \\
\text { thickness }(\mathrm{mm}))\end{array}$ & $\begin{array}{l}\text { Spacer } \\
\text { material }\end{array}$ & $\begin{array}{c}U \text {-value } \\
\left(\mathrm{W} / \mathrm{m}^{2} \mathrm{~K}\right)\end{array}$ & $\begin{array}{c}\text { Test date } \\
\text { (yy.mm.dd) }\end{array}$ \\
\hline 1 & $\begin{array}{l}\text { Stainless steel } \\
\text { and aluminum }\end{array}$ & Swing & Double & 100 & $\begin{array}{c}\text { Low E } 6 \mathrm{~mm} \text {-argon gas } \\
16 \mathrm{~mm} \text {-clear } 6 \mathrm{~mm} \\
\text { Low E } 6 \mathrm{~mm} \text {-argon gas } \\
12 \mathrm{~mm} \text {-clear } 6 \mathrm{~mm}\end{array}$ & PVC & 1.794 & $2015.03 .25-03.26$ \\
\hline 2 & Aluminum & Swing & Single & 150 & $\begin{array}{c}\text { Clear } 6 \mathrm{~mm} \text {-air } 12 \mathrm{~mm} \text {-low } \\
\text { E } 6 \mathrm{~mm}\end{array}$ & PVC & 2.688 & 2015.01.30-01.31 \\
\hline$\sim 532$ & Aluminum & Fixed & Single & 180 & $\begin{array}{l}\text { Low E } 6 \mathrm{~mm} \text {-argon gas } \\
14 \mathrm{~mm} \text {-clear } 5 \mathrm{~mm} \text {-argon } \\
\text { gas } 12 \mathrm{~mm} \text {-low E } 5 \mathrm{~mm}\end{array}$ & PVC & 0.9165 & $2016.04 .22-04.22$ \\
\hline
\end{tabular}

TABLE 2: Window component settings and coding of nominal scale variables for multiple linear regression analysis.

\begin{tabular}{|c|c|c|c|c|c|}
\hline & & & Variables & & \\
\hline Frame material & FR_1 & FR_2 & FR_3 & FR_4 & FR_5 \\
\hline Stainless steel & 1 & 0 & 0 & 0 & 0 \\
\hline Galvanized & 0 & 1 & 0 & 0 & 0 \\
\hline Steel & 0 & 0 & 1 & 0 & 0 \\
\hline Aluminum & 0 & 0 & 0 & 1 & 0 \\
\hline PVC & 0 & 0 & 0 & 0 & 1 \\
\hline Wood & 0 & 0 & 0 & 0 & 0 \\
\hline Window opening type & OP_1 & OP_2 & OP_3 & OP_4 & OP_5 \\
\hline Fixed & 1 & 0 & 0 & 0 & 0 \\
\hline Sliding & 0 & 1 & 0 & 0 & 0 \\
\hline Casement & 0 & 0 & 1 & 0 & 0 \\
\hline Tilt & 0 & 0 & 0 & 1 & 0 \\
\hline Folding & 0 & 0 & 0 & 0 & 1 \\
\hline Turning & 0 & 0 & 0 & 0 & 0 \\
\hline Spacer material & SP_1 & SP_2 & Window number & WD_1 & \\
\hline PVC & 1 & 0 & Single & 1 & \\
\hline Aluminum & 0 & 1 & Double & 0 & \\
\hline Stainless steel & 0 & 0 & & & \\
\hline
\end{tabular}

types of spacer materials, which were divided into SP_1 and 2 . There were two types of window number, which were assigned to WD_1.

Glass and air materials were selected as main elements of glazing, and its thickness, that is, ratio scale variable, is marked in Table 3. Multiple variables were set for each layer so as to ensure correspondence from single glazing to quadruple glazing. Glass materials were simplified: here, LE means low E glass, CL means clear glass, and AG means argon gas [13].

5.2. Multiple Linear Regression Analysis on U-Value. Based on data coding in Section 5.1, multiple linear regression analysis was performed with $U$-value as the dependent variable and the ratio scale variable of glazing elements, which is expected to have considerable effects on the $U$-value, as the independent variable [14]. In the result of regression analysis in (Model 1) Table 4, the modified $R$ value was 0.143 and prediction error of $U$-value was 0.408 , which suggest that it is unreliable to explain $U$-values only using the ratio scale variables related to glazing. Model 2 in Table 4 shows the results of regression analysis in which both nominal scale variables and ratio scale variables were used. The modified
$R$-value was very high, 0.621 , while the prediction error of $U$-value was 0.271 , much lower than that in Model 1 .

In the result of the regression analysis of Model 2, the effects of each independent variable on dependent variables were examined. Among the independent variables, the standardized coefficient (beta) of the nominal scale variable WD_1 (single or double window) was 0.914 and that of $t$ value 17.746 , which indicates excessively high influence. This means the number of windows, that is, whether it is double or single, determines about $0.85 \mathrm{~W} / \mathrm{m}^{2} \mathrm{~K}$ of $U$-value. Therefore, the regression analysis was conducted based on two models: single window and double window.

The results are shown in Table 5. Both Model 3 (single window) and Model 4 (double window) showed lower standard error of the estimate, that is, 0.256 and 0.203 , respectively, than Model 2 in which all independent variables were used and, therefore, better explained the $U$-values. Table 6 shows coefficient analysis of each independent variable for single window and for double window. In the evaluation of the effects of the independent variables on thermal transmission coefficients, for single window, GL_AG2 $>$ GL_AG1 $>$ GL_LE2 $>$ OP_5 $>$ OP_1 > FR_5 > GL_AIR1 > GL_LE1 had the highest effects on thermal transmission coefficients in the order. OP_5 
TABLE 3: Glazing material setting and scale variables for multiple linear regression analysis.

\begin{tabular}{|c|c|c|c|c|c|c|c|}
\hline Layer number & Single layer & \multicolumn{2}{|c|}{ Double layer } & \multicolumn{2}{|c|}{ Triple layer } & \multicolumn{2}{|c|}{ Quadruple layer } \\
\hline Variable & GL_LE1 & GL_AG1 & GL_LE2 & GL_AG2 & GL_LE3 & GL_AG3 & GL_LE4 \\
\hline Label & GL_CL1 & GL_AIR1 & GL_CL2 & GL_AIR2 & GL_CL3 & GL_AIR3 & GL_CL4 \\
\hline Material & Glass & Gas & Glass & Gas & Glass & Gas & Glass \\
\hline
\end{tabular}

TABLE 4: Results of regression analysis with regard to Model 1, 2.

\begin{tabular}{lccccc}
\hline Model & $R$ & $R$ square & Adjusted $R$ square & Standard error of the estimate & Durbin-Watson \\
\hline 1 & $0.401^{\mathrm{a}}$ & 0.161 & 0.143 & 0.4083529 & 1.704 \\
2 & $0.799^{\mathrm{b}}$ & 0.639 & 0.621 & 0.2715533 & 1.552 \\
\hline
\end{tabular}

a Predictors: (constant), GL_CL3, GL_AG2, GL_AG3, GL_LE1, GL_CL1, GL_AIR1, GL_LE3, GL_AIR2, GL_CL2, GL_LE2, and GL_AG1. ${ }^{b}$ Predictors: (constant), WD_1, FR_2, OP_5, OP_4, FR_3, GL_AG3, FR_1, GL_AIR2, GL_CL1, GL_AG2, SP_2, OP_3, GL_LE1, FR_5, GL_LE3, GL_AIR1, GL_CL3, FR_WIDTH, GL_CL2, OP_1, FR_4, GL_LE2, GL_AG1, SP_1, and OP_2.

TABLE 5: Results of regression analysis with regard to Model 3 (single window) and 4 (double window).

\begin{tabular}{lcccccc}
\hline Model & $\begin{array}{c}\text { WD_1 }= \\
\text { (selected) }\end{array}$ & $\begin{array}{c}\text { WD_1 } \\
\text { (unselected) }\end{array}$ & $\begin{array}{c}R \\
\text { square }\end{array}$ & $\begin{array}{c}\text { Adjusted } R \\
\text { square }\end{array}$ & $\begin{array}{c}\text { Standard error of the } \\
\text { estimate }\end{array}$ & $\begin{array}{c}\text { Durbin-Watson statistic } \\
\text { WD_1 }= \\
\text { (selected) }\end{array}$ \\
(unselected) \\
\hline 3 single & $0.827^{\mathrm{a}}$ & 0.297 & 0.683 & 0.661 & 0.2569519 & 1.502 \\
4 double & $0.716^{\mathrm{a}}$ & 0.250 & 0.513 & 0.459 & 0.2039560 & 2.079 \\
\hline
\end{tabular}

aredictors: (constant), SP_2, GL_AG3, FR_1, GL_CL1, GL_CL3, GL_LE1, GL_AG2, FR_5, FR_WIDTH, GL_AIR1, OP_3, GL_LE3, FR_4, GL_AIR2, GL_LE2, GL_AG1, GL_CL2, and SP_1.

TABLE 6: Result of regression analysis: influences of each independent variable on $U$-value.

\begin{tabular}{|c|c|c|c|c|c|c|c|c|}
\hline \multirow{2}{*}{ Variables } & \multicolumn{4}{|c|}{ Single window } & \multicolumn{4}{|c|}{ Double window } \\
\hline & $B$ & $\beta$ & $t$ & Significance & $B$ & $\beta$ & $t$ & Significance \\
\hline (Constant) & 2.718 & & 16.524 & 0.000 & 2.384 & & 8.659 & 0.000 \\
\hline FR_1 & -0.032 & -0.017 & -0.422 & 0.673 & 0.038 & 0.010 & 0.118 & 0.906 \\
\hline FR_2 & 0.064 & 0.008 & 0.240 & 0.810 & - & - & - & - \\
\hline FR_3 & 0.228 & 0.061 & 1.776 & 0.077 & - & - & - & - \\
\hline FR_4 & 0.057 & 0.058 & 0.994 & 0.321 & 0.428 & 0.774 & 7.722 & 0.000 \\
\hline FR_5 & -0.165 & -0.173 & -3.484 & 0.001 & 0.194 & 0.333 & 3.705 & 0.000 \\
\hline OP_1 & -0.320 & -0.359 & -3.576 & 0.000 & - & - & - & - \\
\hline OP_2 & 0.086 & 0.085 & 1.048 & 0.295 & - & - & - & - \\
\hline OP_3 & -0.168 & -0.175 & -1.801 & 0.073 & -0.061 & -0.023 & -0.253 & 0.801 \\
\hline OP_4 & -0.232 & -0.056 & -1.441 & 0.151 & - & - & - & - \\
\hline OP_5 & 0.867 & 0.148 & 3.894 & 0.000 & - & - & - & - \\
\hline FR_WIDTH & - & - & - & - & -0.005 & -0.393 & -5.274 & 0.000 \\
\hline GL_LE1 & -0.036 & -0.114 & -2.977 & 0.003 & -0.046 & -0.383 & -2.799 & 0.006 \\
\hline GL_AG1 & -0.036 & -0.469 & -5.880 & 0.000 & -0.009 & -0.191 & -1.651 & 0.101 \\
\hline GL_CL1 & -0.030 & -0.161 & -2.747 & 0.006 & 0.010 & 0.037 & 0.406 & 0.685 \\
\hline GL_AIR1 & -0.021 & -0.236 & -3.031 & 0.003 & -0.009 & -0.181 & -1.648 & 0.101 \\
\hline GL_LE2 & -0.045 & -0.285 & -4.302 & 0.000 & 0.031 & 0.204 & 1.599 & 0.112 \\
\hline GL_AG2 & -0.029 & -0.343 & -6.085 & 0.000 & -0.030 & -0.354 & -3.053 & 0.003 \\
\hline GL_CL2 & 0.034 & 0.110 & 2.864 & 0.004 & 0.026 & 0.235 & 1.546 & 0.124 \\
\hline GL_AIR2 & -0.049 & -0.180 & -4.726 & 0.000 & -0.012 & -0.160 & -1.359 & 0.176 \\
\hline GL_LE3 & -0.096 & -0.107 & -2.931 & 0.004 & -0.048 & -0.127 & -1.195 & 0.234 \\
\hline GL_AG3 & - & - & - & - & 0.000 & -0.002 & -0.017 & 0.986 \\
\hline GL_CL3 & 0.055 & 0.085 & 2.232 & 0.026 & 0.029 & 0.193 & 1.782 & 0.077 \\
\hline SP_1 & -0.056 & -0.051 & -0.630 & 0.529 & -0.103 & -0.179 & -1.036 & 0.302 \\
\hline SP_2 & 0.117 & 0.110 & 1.309 & 0.191 & -0.082 & -0.144 & -0.800 & 0.425 \\
\hline
\end{tabular}

(folding opening window) had an effect on increasing thermal transmission coefficients, while argon gas, low $\mathrm{E}$ glass, fixed window, PVC frame, and air gap had effects on decreasing thermal transmission coefficients (i.e., increasing thermal performance). As for double window, FR_4 $>$ FR_width $>$ GL_LE1 $>$ GL_AG2 $>$ FR_5 had the 
highest effects on thermal transmission coefficients in the order. Because it has two windows, double window is considered to be more influenced by frame components than by glazing components and window opening type, comparing to single window. . In other words, aluminum frame and PVC frame have effects on increasing thermal transmission coefficients, while frame width, argon gas, and low E glass have substantial effects on lowering thermal transmission coefficients.

Based on the results above, this study proposed two regression equations for simple estimation of thermal transmission coefficients for window systems by using their components as follows:

For single window,

$$
\begin{aligned}
2.718 & -0.032 \mathrm{FR} 1+0.064 \mathrm{FR} 2+0.228 \mathrm{FR} 3+0.057 \mathrm{FR} 4-0.165 \mathrm{FR} 5-0.320 \mathrm{OP} 1+0.086 \mathrm{OP} 2-0.168 \mathrm{OP} 3-0.232 \mathrm{OP} 4 \\
& +0.867 \mathrm{OP} 5-0.036 \mathrm{GLLE} 1-0.030 \mathrm{GLCL} 1-0.036 \mathrm{GLAG} 1-0.021 \mathrm{GLAIR} 1-0.045 \mathrm{GLLE} 2+0.034 \mathrm{GLCL} 2 \\
& -0.029 \mathrm{GLLE} 2+0.034 \mathrm{GLCL} 2-0.096 \mathrm{GLLE} 3+0.053 \mathrm{GLCL} 3-0.056 \mathrm{SP} 1+0.117 \mathrm{SP} 2=U-\mathrm{value}\left(\mathrm{W} / \mathrm{m}^{2} \mathrm{~K}\right)
\end{aligned}
$$

For double window,

$$
\begin{aligned}
2.384 & +0.038 \mathrm{FR} 1+0.428 \mathrm{FR} 4+0.194 \mathrm{FR} 5-0.061 \mathrm{OP} 3-0.005 \text { FRWIDTH }-0.046 \mathrm{GLLE} 1+0.010 \mathrm{GLCL} 1-0.009 \mathrm{GLAG} 1 \\
& -0.009 \mathrm{GLAIR} 1+0.031 \mathrm{GLLE} 2+0.026 \mathrm{GLCL} 2-0.03 \mathrm{GLAG} 2-0.012 \mathrm{GLAIR} 2-0.048 \mathrm{GLLE} 3+0.029 \mathrm{GLCL} 3 \\
& -0.103 \mathrm{SP} 1-0.082 \mathrm{SP} 2=U-\text { value }\left(\mathrm{W} / \mathrm{m}^{2} \mathrm{~K}\right) .
\end{aligned}
$$

where the expected errors of thermal transmission coefficients are $0.2569 \mathrm{~W} / \mathrm{m}^{2} \mathrm{~K}$ in (1) and (0.2039) W/m $/ \mathrm{m}^{2} \mathrm{~K}$ in (2).

\section{Conclusion}

In this study, based on the performance test data of thermal transmission coefficients related to 532 window systems, window components were selected for regression analysis. And this study proposed two regression equations that can be simply used when selecting window components in the design stage and drew the following conclusions:

In the regression analysis using all independent variables that compose window systems (i.e., frame material, window opening type, window number (single or double), frame width, glazing detail, and spacer material), the modified $R$ value was very high, 0.621 , and the prediction error of $U$-value was 0.271 .

Regarding importance of the variables, the nominal scale variable WD_1 (single or double window) had the standardized coefficients (beta) value of 0.914 and $t$ value of 17.746, which indicated excessively strong effects. The number of windows, that is, whether it is double or single, also determined about $0.85 \mathrm{~W} / \mathrm{m}^{2} \mathrm{~K}$ of $U$-value.

WD_1, which had a substantial effect on $U$-value, was separated and divided into two models_-single window and double window-in order to perform regression analysis and, subsequently, establish two regression equations. For single window, the predicted error of thermal transmission coefficients was $0.2569 \mathrm{~W} / \mathrm{m}^{2} \mathrm{~K}$, and for double window, $0.2039 \mathrm{~W} / \mathrm{m}^{2} \mathrm{~K}$.

The regression equations for predicting thermal transmission coefficients proposed in this study had slight errors. Future research will need to divide and evaluate window system components more specifically and compare new measurement data of thermal transmission coefficients and values predicted based on regression equations. Furthermore, to reduce errors, it will need to develop an algorithm to predict thermal transmission coefficients using the neural network theory and so on.

\section{Conflicts of Interest}

The authors declare that there are no conflicts of interest.

\section{Acknowledgments}

This work (201702700001) was supported by Business for R\&D funded Korea Small and Medium Business Administration in 2017. This was supported by Korea National University of Transportation in 2017.

\section{References}

[1] Ministry of Environment, Korea, In 2030, Korea's Greenhouse Gas Reduction Target Was Set at 37\% of the Target BAU (851 Million Tons), Press Releases, 2014.

[2] T. H. Lee, "Paris agreement and urban energy conversion," Space and Society, vol. 26, no. 1, 2016.

[3] F. Asdrubali and G. Baldinelli, "Thermal transmittance measurements with the hot box method: calibration, experimental procedures, and uncertainty analyses of three different approaches," Energy and Buildings, vol. 43, no. 7, pp. 1618-1626, 2011.

[4] S. Yoo, H. Jeong, B.-L. Ahn et al., "Thermal transmittance of window systems and effects on building heating energy use and energy efficiency ratings in South Korea," Energy and Buildings, vol. 67, pp. 236-244, 2013.

[5] S.-H. Kim, S.-S. Kim, K.-W. Kim, and Y.-H. Cho, "A study on the proposes of energy analysis indicator by the window 
elements of office buildings in Korea," Energy and Buildings, vol. 73, pp. 153-165, 2017.

[6] S.-T. No, K.-S. Kim, and J.-S. Jung, "Simulation and mock-up tests of the thermal performance of curtain walls," Energy and Buildings, vol. 40, no. 7, pp. 1135-1144, 2017.

[7] KS F 2278 91.060.50, Standard Test Method for Thermal Resistance for Windows and Doors, KSA Publishing, Saudi Arabia, 2014.

[8] ISO 12567-1 91.120.10, 91.060.50, Thermal Performance of Windows and Doors-Determination of Thermal Transmittance by the Hot-Box Method-Part 1: Complete Windows and Doors, 2010.

[9] ISO 8990 27.220, Thermal Insulation-Determination of Steady-State Thermal Transmission Properties-Calibrated and Guarded Hot Box, 1994.

[10] http://www.kcl.re.kr/site/homepage/menu/viewMenu?menuid= 001001001001\#.

[11] https://www.ibm.com/analytics/data-science/predictive-analytics/ spss-statistical-software.

[12] H. Seo, Regression Analysis (SPPSS PAWS), Hannarae academy, Seoul, Republic of Korea, 2013.

[13] M. H. Kutner, J. Neter, and J. Nachtsheim, Applied Linear Statistical Models, McGraw-Hill/Irwin, New York, NY, USA, 2004.

[14] M. J. Norusis, SPSS 16.0 Statistical Procedures Companion, Prentice-Hall, Upper Saddle River, NJ, USA, 2008. 


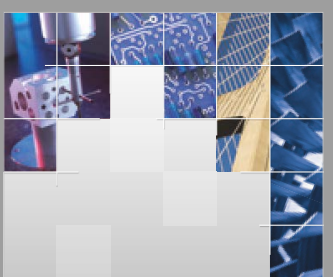

\section{Enfincering}
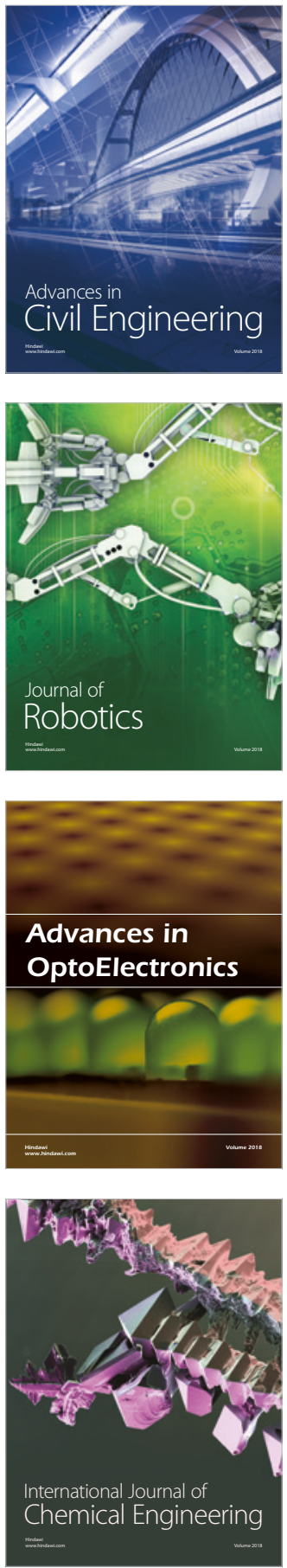

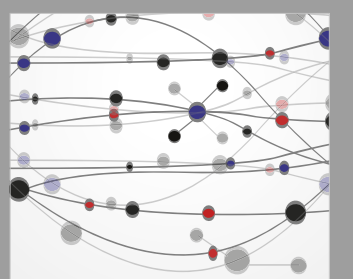

\section{Rotating \\ Machinery}

The Scientific World Journal

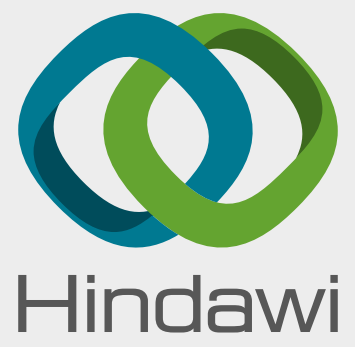

Submit your manuscripts at

www.hindawi.com
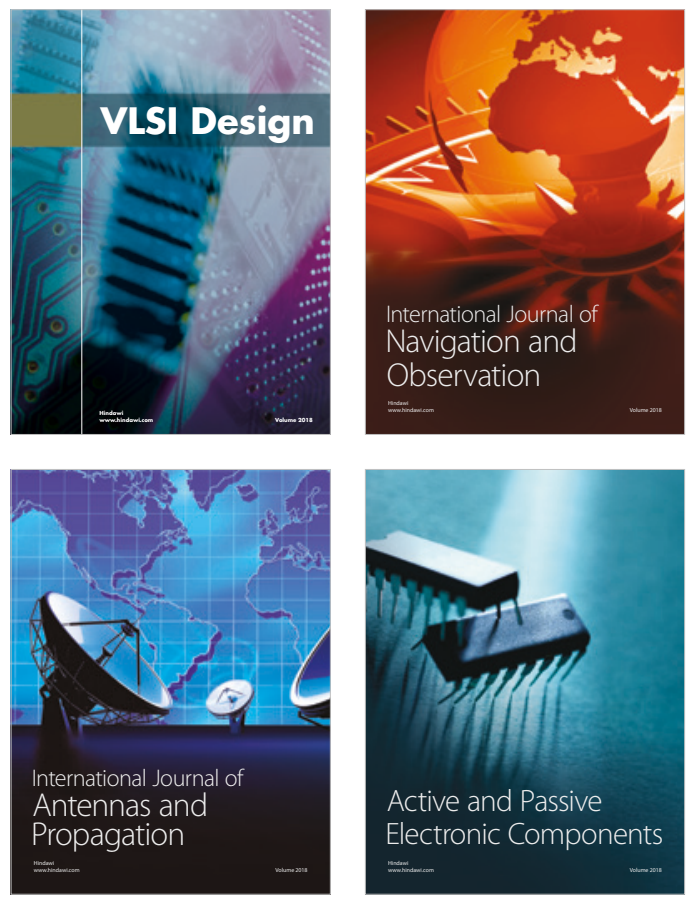
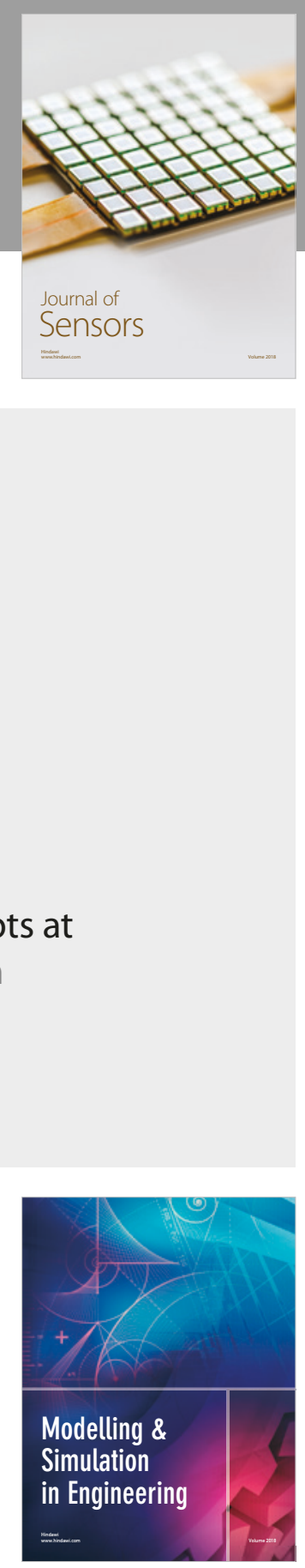

\section{Advances \\ Multimedia}
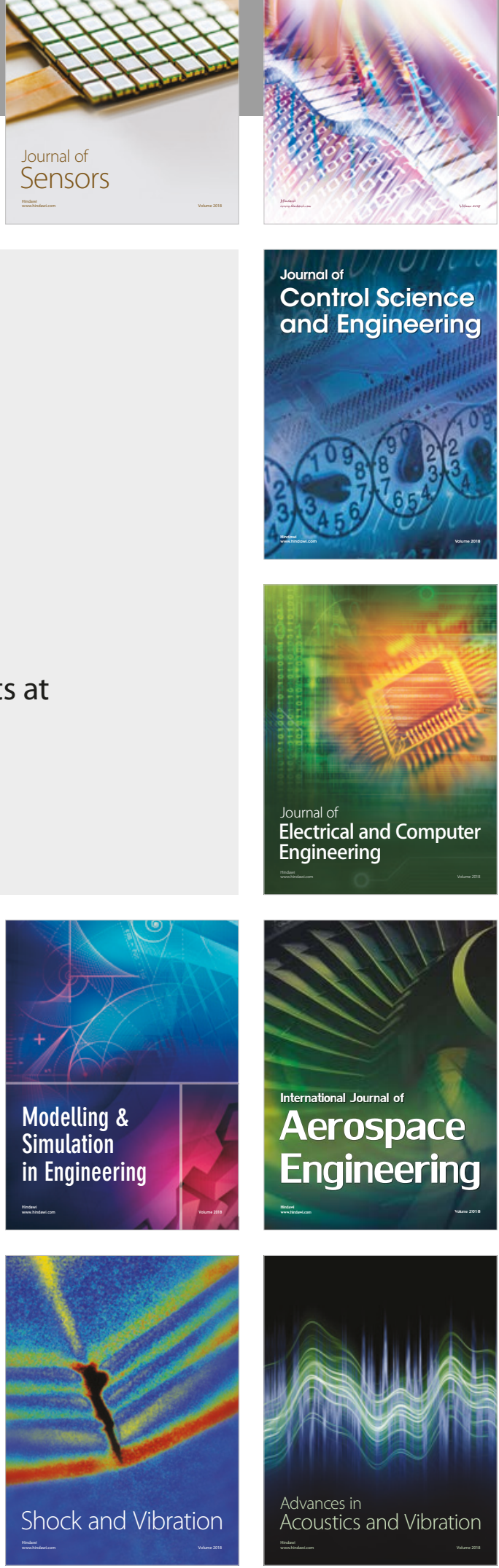